\title{
THE CONSULTATIVE DRAFTING PROCESS FOR CHINESE EMISSIONS TRADING REGULATION: EFFECTIVE INPUTS BUT UNCERTAIN OUTPUT
}

\author{
STEVEN GEROE \\ Faculty of Law, La Trobe University, Melbourne, Australia.
}

\begin{abstract}
The interviews informing this paper provide a series of interlocking case studies of the ways in which specialist expertise in renewable energy institutions is integrated through the consultative drafting processes for Chinese emission trading schemes (ETS). This has been implemented through drafting groups, research collaboration, various types of meetings and conferences, industry feedback and online solicitation of opinions. Interviews in state-related research institutions, universities, regional ETS carbon exchanges and private sector consultancies indicated that this process can be a useful means of integrating regulatory measures that have proven effective. Not all interviewee recommendations are reflected in the February 2021 Trial Measures for the Chinese national ETS and related implementing rules. Examples of adoption of interviewees' recommendations included detailed requirements for emissions monitoring plans, models for trading systems and registries, and specific methodologies such as default emissions values. The most important examples of non-adoption were stringent penalties for emissions and monitoring, reporting and verification (MRV) offences and supervisory powers of regulators relating to third-party inspection organisations. The March 2021 opinion solicitation draft (OSD) for a higher level, more permanent State Council regulation contains stronger penalties and supervisory powers. The 2019 and 2020 OSDs for the current national ETS rules also contained stronger penalties and supervisory powers than the current rules. Hence, all of the OSDs more closely resemble interviewee recommendations than the current rules. Interview evidence, and related scholarly writing, suggests that this pattern may relate to resistance of powerful economic interests. Nonetheless, it suggests that such resistance can be countered through capacity building and the example of early adopters in effective emissions trading. While the consultative drafting process has proved a useful means for identifying effective regulatory design on the basis of pilot ETS experience, it has yet to be put to best effect in the current national ETS rules.
\end{abstract}

Keywords: carbon price, Chinese, consultative drafting, emissions trading, regulation, renewable energy.

\section{INTRODUCTION}

The interviews informing this paper provide a series of interlocking case studies of the ways in which specialist expertise in renewable energy institutions is integrated through the consultative drafting processes for Chinese emission trading schemes (ETS). It does not purport to provide an account of all institutions and processes involved. Rather, it provides illustrative examples of means by which stakeholders interviewed provided input into the ETS drafting process on design features they regarded as critical. This addresses a gap in the research on stakeholder engagement in the drafting of the national ETS. As Stoerk et al. note, 'The academic literature on this point is scarce' [1].

The National Development and Reform Commission (NDRC) and the Ministry of Ecology and Environment (MEE) have in turn coordinated the input of a range of institutional stakeholders into the regulatory process. This has largely been implemented through drafting groups, research collaboration, various types of meetings and conferences, industry feedback and online solicitation of opinions. Interview responses indicated that the consultative drafting process can be a useful means of integrating regulatory measures that have proven 
effective. Research interviews were conducted in state-related research organisations, universities, carbon trading exchanges and private sector entities involved in ETS drafting in Beijing, Tianjin, Guangzhou and Wuhan, from December 2019 to January 2020. A semistructured interview format was adopted. This involved follow-up questions exploring responses to general questions on integration of learning from the pilots into ETS rules through institutional involvement in consultative drafting. This enabled flexibility in pursuing examples of regulatory approaches within interviewees' own experience. The paper is structured to examine the contribution of different types of institution in the consultative drafting process for the regional pilot and the Chinese national ETS.

A number of interviewee recommendations are not reflected in the February 2021 Trial Measures for the Chinese national ETS and related implementing rules. Examples of adoption of interviewees' recommendations included detailed requirements for emissions monitoring plans, models for trading systems and registries, and specific methodologies such as default emissions values. The most important examples of non-adoption were stringent penalties for emissions and monitoring, reporting and verification (MRV) offences and supervisory powers of regulators relating to third-party inspection organisations. The March 2021 opinion solicitation draft (OSD) for a higher level, more permanent State Council regulation contains stronger penalties and supervisory powers. The 2019 and 2020 OSDs for the current national ETS rules also contained stronger penalties and supervisory powers than the current rules. Hence, all of the OSDs more closely resemble interviewee recommendations than the current rules. Interview evidence, and related scholarly writing, suggests this pattern may relate to resistance of powerful economic interests. Nonetheless, it suggests that such resistance can be countered through capacity building and the example of early adopters in effective emissions trading. While the consultative drafting process has proved a useful means for identifying effective regulatory design on the basis of pilot ETS experience, it has yet to be put to best effect in the current national ETS rules.

\section{INTERVIEW EVIDENCE}

\subsection{Regional pilot ETS}

The State Council has been responsible for the development of the regional pilots and the Chinese national ETS, as part of its administrative function of drawing up and implementing five-year plans for China's economic and social development [2]. As such, the national legislature, the National People's Congress (NPC), has not been directly involved in either regional or national ETS development. The seven regional ETS pilots were initiated by planning documents and rules of the NDRC [3], formerly known as the State Planning Commission. The regional pilots have been implemented by a combination of Local People's Congress (LPC) rules [3], [4] and [5], and rules of sub-national departments of the NDRC and subsequently the MEE. These sub-national rules have provided the implementation detail for the broad principles and objectives set out by the NDRC [6]. (The Chinese Legislation Law sets out a hierarchy of legislative authority, in descending order as follows: laws of the NPC, national administrative regulations of the State Council and rules of central government departments made to implement State Council regulations or decisions. Rules made by sub-national People's Congresses rank higher than rules of sub-national executive government ministries) [7].

With regard to the consultative drafting process of the regional pilots, Guangdong is taken as an example due to the detailed interview evidence provided. In 2011, the NDRC selected 
Guangdong as one of seven pilot ETS. Several institutions participated in a working group led by the Guangdong Development and Reform Commission (the Guangdong DRC). These included the Guangdong Research Centre for Climate Change at Sun Yat-sen University, the Guangzhou Energy Research Centre of the Chinese Academy of Sciences, the Guangdong section of the Chinese Academy of Social Sciences, the China Quality Certification Centre and the Ministry of Industry and Information. Research topics for reports to the Guangdong DRC were allocated to each of these institutions. Interviewee Zeng Xuelan participated as Director of the Guangdong Research Centre for Climate Change at Sun Yat-sen University [8]. Three regulations were drafted: for MRV, quota allocation and management of the whole ETS (including trading). Specific annual allocation plans were also drafted.

The working group initially focused on MRV. As the emissions volume of the covered enterprises was unknown, the working group visited and studied the data and statistical systems of the more than three hundred covered enterprises and government institutions. This involved close cooperation with the relevant industry organisations. In the first phase, the power, iron and steel, and petrochemicals industries were covered, followed by the aviation and paper-making industries. Zeng Xuelan indicated that: 'Local industry organizations made an important contribution [to scheme design]. We sought their suggestions, at meetings and through written submissions. At the start our main focus was on researching Guangdong enterprises, and studying the EU and Californian ETS.' The working group also had close cooperation with experts on the EU and Californian ETS, through research meetings.

Requirements for emissions monitoring plans are specified in the Guangdong MRV rules [9]. Since 2018, Guangdong (unlike some pilots) has required monitoring plans, set deadlines and required information, such as monitoring boundaries of the company, monitoring methods and data selection [8]. Pilot experience shows that requiring adequate monitoring plans improves data quality, and monitoring and reporting of emissions [4] and [23]. Zeng Xuelan indicated that the most important lesson from experience of monitoring plans in Guangdong is that they should not be revised in the absence of important changes to the enterprise's situation. Otherwise, they should only be changed to make the requirements more stringent. As monitoring plans are drafted by covered entities, this requirement could prevent any weakening of monitoring requirements by entities without adequate justification. Under MRV guidelines for enterprises in the national ETS issued by the MEE in March 2021, Data Quality Control Plans can only be amended in specified circumstances. These include where new emissions are due to changes in facilities, fuels or materials; where new methods or instruments are adopted to improve data accuracy; and where existing monitoring methods are incorrect, can be improved or do not meet requirements [10]. Data Quality Control Plans must include, among other things, accounting boundaries and methods, production data, emissions factors and measures for internal data quality control. They must comply with all applicable MEE emissions accounting guidelines, and technical specifications and standards [10]. While these requirements are consistent with interviewees' recommendations, they are contained in an MEE departmental guideline without applicable penalties for non-compliance. The financial penalty for false emissions reporting in the 2021 Trail Measures Article 39 applies to GHG reports submitted to the MEE, not Data Quality Control Plans. The maximum penalty of 30,000 RMB in that provision is much lower than 200,000 RMB in both the 2019 OSD [11] and the March 2021 OSD for a State Council regulation [12].

Zeng Xuelan also referred to Guangdong's approach to supervision of emissions verification organisations. While under Beijing pilot rules, the MEE selects some third-party verifiers to check other inspection agencies' reports; in Guangdong, all third-party verifiers must be 
registered. All third-party verification reports are cross checked by other inspection organisations, as opposed to only selected reports being checked as in the other pilots. If mistakes are discovered, a further spot verification is conducted. If no mistakes are discovered, some results are sampled and subjected to spot checks on the enterprise. Additionally, an evaluation system for third-party verifiers involves a score based on evaluation rules. The score is based on the number of errors in the report and the occurrence of any illegal conduct such as conflict of interest. A third-party verification blacklist precludes third-party verifiers receiving work for the following 12 months [8].

Article 31 of the 2021 Trial Measures requires the MEE to implement verification work according to the 'double random one open' method, meaning random selection of inspection subjects and inspectors, and public disclosure of inspection outcomes [13]. It also empowers local MEE departments to determine the focus and frequency of inspections, on the basis of verification outcomes on liable entities' emissions reports. It does not refer to powers to make spot checks and to check and/or copy relevant documents and materials, or trading-related information systems and monitoring facilities in the manner of 2019 OSD Article 18. Article 22 of the 2021 OSD for a State Council regulation is stronger in this regard, as it provides that the MEE shall supervise and manage both trading entities and verification organisations through onsite inspections, copying, checking and investigating relevant documents, materials and information systems, and requiring explanations for any relevant issues. Additionally, the MEE shall establish a mechanism for sharing information and facilitating law enforcement with market, banking and securities regulatory authorities. Nonetheless, there is a need for subsequent regulations to provide penalties for the full range of misconduct specified by the 2021 MEE MRV rules. This includes accepting funding from Key Emissions Entities, participating in carbon asset management or carbon trading activities, sharing personnel with Key Emissions Entities being verified and using inspectors with a conflict of interest [10]. While a credible approach, the double random one open method is a less comprehensive means of supervising verification organisations than the measures adopted in Guangdong. Combining the supervisory measures in the Guangdong pilot with stronger MEE investigative powers, and financial penalties for all conduct prohibited by MEE rules for verification organisations, would provide a stronger regulatory basis for reliable MRV data.

State-related research institutions have also contributed to the development of the Tianjin pilot ETS. While Tianjin Academy of Environmental Science (TAES) research covers environmental issues more broadly, the Tianjin Low-carbon Research Centre (TLCRC) is more specifically focused on ETS research, particularly relating to MRV. For example, a methodology for emissions calculations for steelmaking based on industrial processes as opposed to financial factors was developed at the TLCRC for the Tianjin ETS, which will be adopted in the national ETS [6]. TLCRC is also engaged in research on other ETS design elements, such as permit allocation. TAES and TLCRC are both specialised research centres affiliated with the Tianjin bureau of the MEE. This research is complementary to that of Nankai University, which is responsible for the MRV system and regulations. The Tianjin Carbon Emissions Trading Exchange (TCX) is involved in development of market trading rules and related systems. The Tianjin University of Science and Technology provides expertise on measurement and quantification and other technical aspects of data provision relevant to MRV, permit allocation and other elements of ETS operation [6]. TAES and TLCRC participate in consultative drafting, through meetings organised by the MEE, typically when new policies are introduced. They can be held in Beijing or one of the pilot cities [6]. 


\subsection{The national ETS}

The MEE coordinates consultation with its specialist research institutions and with industry organisations on the ETS, through meetings and conferences. It has coordinated many rounds of consultation with ministries and government agencies involved in the ETS. These include the Ministry of Finance, the Ministry of Commerce, the Ministry of Industry and Information, the Ministry of Science and Technology, the China Civil Aviation Authority and the China Securities Regulatory Commission [14]. It also publishes OSD rules for the national ETS on its website [11] and [15]. Duan Maosheng indicated that the Institute of Energy, Environment and Economy (IEEE) at Tsinghua University was responsible for drafting the 'specific language' of the OSDs for the national ETS regulations. It reports to the MEE on whether suggestions should be included or taken into account in the revised rules. Tsinghua is the only university involved on an institutional basis in drafting the national ETS rules [14]. Individual academics from several universities including the China University of Politics and Law also contribute. The Guangdong Research Centre for Climate Change at Sun Yat-sen University has also supported the MEE through submissions on the OSDs for the national ETS, and indirectly by providing research and suggestions to the Guangdong provincial government, who pass them on to the MEE [8]. The IEEE has members from disciplines including engineering, energy, and finance and economics.

Duan Maosheng indicated that penalties imposed per $\mathrm{t} / \mathrm{CO} 2 \mathrm{e}$ can be a stronger disincentive for excess emissions than one-off fines. The Beijing ETS imposes financial penalties set at three times the average market prices per $\mathrm{t} / \mathrm{CO} 2 \mathrm{e}$ for excess emissions up to $10 \%$ of allocations, five times for excess of over $20 \%$ and four times for $11-20 \%$ [16]. He indicated this penalty was a factor for achieving high rates of compliance. This model was adopted in Article 19 of the 2019 OSD for the national ETS. It provided that, following expiration of a warning period, the local bureau of the MEE can impose a penalty 2-5 times the average market price per t/CO2e for that year [11]. Article 40 of the 2021 ETS Trial Measures provides for one-off fines of 20,000-30,000 RMB. Where the shortfall is not corrected within a specified deadline, the amount of the shortfall shall be deducted from the following year's quota allocation [17]. Article 25 of the March 2021 OSD for a State Council national ETS regulation follows the same approach, but with substantially higher fines of 100,00-500,000 RMB. While the threat of a correspondingly tighter emissions allocation creates additional incentive for performance, it may be less stringent than a penalty applied per $\mathrm{t} / \mathrm{CO} 2 \mathrm{e}$ for more significant shortfalls.

Carbon exchanges have played a significant role in drafting trading rules and administrative support systems such as registries, trading platforms and clearance mechanisms. For example, the China Hubei Emission Exchange has participated in consultative drafting through workshops on key issues for the national ETS, along with representatives of the other pilots, the big electricity companies, industry associations and universities. It is a company owned by the Hubei provincial government [18]. The President of the Hubei exchange also contacts the MEE directly, providing a further channel for involvement in regulatory development. The Hubei exchange proposal for design of the registry for the national ETS was selected for implementation by the MEE [19]. Based on the existing Hubei registry, it incorporated improvements based on lessons from implementation experience. Tian Yiran stated that the essential priorities are for the system to be easy to use and control and to provide security for carbon asset sales. For example, the existing coding system based on the EU ETS has a unique identifier for each discrete ton of GHG. The proposed model will have a 
common code for all tons of GHG from the same source/entity. This will be more efficient and will reduce the burden on the IT and administrative system. Special accounts can be created for related companies, to manage carbon assets on the registry in one account. Fields can be created for separate entries to differentiate between parties with different roles in carbon asset management in the same entity, such as personnel responsible for making and reviewing applications. This capability also facilitates development of enterprises' carbon asset management systems 18].

The China Beijing Environmental Exchange (CBEX) is also a state-owned company, owned by the Beijing municipal government. It prepares reports for the MEE on the performance of the Beijing pilot, available on its website [20]. The Guangdong Climate Exchange and the TCX are also involved in consulting on ETS trading rules [6, 8]. The Shanghai pilot proposal for the trading system for carbon units has been selected for the national ETS [21]. Additionally, all carbon exchanges conducted capacity building programs to support compliance by covered entities [22]. Yu Zexia said that:

'In Hubei, in the first year of the pilot, many companies were angry about the ETS regulation and not afraid to show it. They refused to comply or buy allowances or register accounts at the exchange. We encouraged the companies to participate. In 2014 we held seven capacity building sessions, training companies how to participate. When some companies made some revenue under the trading system others became more willing to participate.'

In this way, capacity building programs implemented by the exchanges were an important element in ensuring participation and compliance by covered entities. This role, together with tendering to the MEE to design operational elements of the national ETS, is additional methods of contributing to ETS development, alongside collaborative research, meetings and direct communication with government.

SinoCarbon Innovation and Investment Ltd. is a private sector entity mentioned by a number of interviewees as closely involved with the consultative drafting process for the national ETS $[8,18,20]$. It is a consulting company and also provides third-party emissions verification services. It does not engage in carbon trading or carbon asset management. It produces software used by firms in carbon accounting and trading, MRV and data management. It works with both government and business, and it is involved in projects supporting provincial governments to prepare for the national ETS and on MRV guidelines for specific sectors [22]. It has been involved in cooperative projects with the World Bank, the Asian Development Bank and the international consulting company ICF. It has received EU funding for projects to support policy dialogue, involving communication between policy makers from the EU and China, as well as capacity building for local officials, MEE officials and industry executives. These projects have covered topics including MRV training of technical staff and trading simulation. Such EU-China joint capacity building projects have been implemented in all provinces. Other project partners of SinoCarbon include Tsinghua University, the National Climate Strategy Center, the World Bank Partnership for Market Readiness and the International Carbon Action Partnership (ICAP). SinoCarbon provides an annual report to ICAP on the Chinese ETS and contributes to ICAP international carbon market reports. SinoCarbon is involved in consulting for the MEE with regard to the rules for the national ETS, e.g. offset rules [22].

Similarly to Zeng Xuelan, Guo Wei of SinoCarbon recommends legislative requirements for monitoring plans covering 'monitoring boundaries of the company (the source streams, emission sources, activities, etc.), the monitoring methodology (e.g. default values, sampling standards), methods used to determine the different parameters such as emission factors, 
description of the quality assurance and the quality control system, included in uniform national templates for monitoring plans [4, 22. Similarly to Duan Maosheng, he referred to the inadequacy of some one-off fines as a deterrent for excess emission, as in Shanghai, where the level of the fine was on average lower than the marginal cost of abatement for emissions.

The MEE also consults directly with the China Electricity Commission (CEC), regarding allocation methods under the OSD process [22]. Other industry groups such as power and steel organisations are also consulted directly or through workshops and meetings [14]. For example, the China Huadian Corporation, one of the five large state-owned power companies in China, helped to develop a low carbon plan to minimise the impacts of national ETS [22]. The MEE also seeks written responses from industry groups and local governments on ETS design issues [14].

\section{CONCLUSIONS}

Interview evidence suggests that the consultative drafting process is an effective means of integrating specialist expertise into ETS regulatory development. Nonetheless, the input of specialist expertise is clearly not a guarantee of its inclusion in ETS rules. In some cases, such as the development of guidelines for monitoring plans, regulatory output is quite consistent with interviewees' recommendations. Conversely, the level of penalties for emissions and MRV offences in current national ETS rules is less stringent than interviewee recommendations, and provisions for supervision of third-party verification organisations are less rigorous. In these regards, the provisions of the 2021 Trial Measures are less stringent than those in the 2019 and 2020 OSDs for MEE rules, and the 2021 OSD for a future State Council regulation. This may reflect resistance to ETS implementation from some stakeholders. As Duan et al. observe: 'During the starting period of China's national ETS, policy makers must fully consider the possibility of enterprises underestimating the government's determination to enforce ETS, large enterprises being united to reject responsibilities, enterprises misunderstanding the role of ETS and lacking awareness of carbon asset management, and reluctant sellers in the allowance market' [23]. Consistently with Hubei interviewees, they emphasise capacity building as a primary means of overcoming such resistance. Commercial stakeholders have not been the only parties resistant to national ETS implementation, with some local government officials 'concerned that the national system will worsen the economic situation and thus be resistant to this policy' [sic] [24]. While the consultative drafting process has proved a useful means for identifying effective regulatory design on the basis of pilot ETS experience, it has yet to be put to best effect in the current national ETS rules. That will require addressing stakeholder resistance through capacity building, familiarisation through successful emissions trading, and commitment to sufficiently stringent measures in a higher level, more permanent State Council regulation.

\section{REFERENCES}

[1] Stoerk, T., Dudek, D.J. \& Yang, J., China's national carbon emissions trading scheme: lessons from the pilot emission trading schemes, academic literature, and known policy details. Climate Policy, 19(4), pp. 472-486, 2019. https://doi.org/10.1080/14693062.2 019.1568959

[2] Constitution of the People's Republic of China [中华人民共和国宪法], National People's Congress (adopted and effective on 4 December 1982; amended on 12 April 1988, 29 March 1993, 15 March 1999, 14 March 2004 and 11 March 2018). 
[3] Guidelines for Accounting and Reporting GHG Emissions for Key Enterprises; NDRC 2013, 2014 and 2015; Interim Measures for the Administration of Carbon Emissions Trading, NDRC 2014; Notice on Implementation of Activities to set up Carbon Emissions Trading Market, NDRC 2016.

[4] Tang, R., Guo, W., Oudenes, M., Li, P. \& Tang, J., Key challenges for the establishment of the monitoring, reporting and verification (MRV) system in China's national carbon emissions trading market. Climate Policy, 18, Supplement 1, pp. 106-121, 2018. https://doi.org/10.1080/14693062.2018.1454882

[5] Peng, F. \& Yan, L., The institutional comparison research of 7 pilot ETS-based on the review on the legal documents of the 7 pilots. China Environment Law, 2, pp. 25-45 2014.

[6] Interview with Wang Dai, Li Zhou and Zhang Lin, offices of the Tianjin bureau of the MEE, 16 December 2019. Wang Dai is a member of the Tianjin Academy of Environmental sciences. Li Zhou and Zhang Lin are members of the Tianjin Low-Carbon Research Centre.

[7] Legislation Law of the People's Republic of China [中华人民共和国立法法], National People's Congress (adopted on 15 March 2000, effective on 1 July 2000 and amended on 15 March 2015), Articles 7, 8, 11, 56, 71 and 73.

[8] Interview with Zeng Xuelan and Li Weichi, Sun Yatsen University, 4 January 2020. The Low-Carbon Research Centre of Sun Yat-sen University was the forerunner of the Guangdong Research Centre for Climate Change.

[9] Guangdong Development and Reform Commission (DRC) Notice on Implementation Measures on Monitoring, Reporting and Verification of Carbon Emissions for Enterprises in Guangdong (Trial) [广东省发展改革委关于印发《广东省企业碳排放信息 报告与核查实施细则 (试行) 》的通知], Guangdong DRC Order No. (2014) 145, 18 March 2014.

[10] Notice on Enterprise GHG Emissions Reporting Verification Guide (trial) 关于印发 《企业温室气体排放报告核查指南 (试行)》的通知, MEE 26 March 20201, [4.2.1.6.1 a)], 2.3 and [4.1.1], with detail at 4.2.1.1 - 4.2.1.7. http://www.mee.gov.cn/ xxgk2018/xxgk/xxgk06/202103/t20210329_826480.html

[11] MEE, 'Carbon Emissions Trading Management Interim Regulations (Opinion Solicitation Draft)' [碳排放权交易管理暂行条例 （征求意见稿）] 3 April 2019, available at: https://www.mee.gov.cn/hdjl/yjzj/wqzj_1/201904/t20190403_698483.shtml

[12] Interim Regulations on the Administration of Carbon Emissions Trading (Revised Draft) 碳排放权交易管理暂行条例 (草案修改稿) http://www.mee.gov. cn/xxgk2018/xxgk/xxgk06/202103/W020210330371577301435.pdf English translation http://www.cet.net.cn/uploads/soft/202104/1_15100052.pdf

[13] International Carbon Action Partnership, China publishes two major policy draft for national ETS, November 2020. https://icapcarbonaction.com/en/news-archive/728china-publishes-two-major-policy-drafts-for-national-ets

[14] Interview with Duan Maosheng, Tsinghua University Beijing, 20 December 2019. Duan Maosheng is the Director of the Institute of Energy, Environment and Economy, Tsinghua University; and Director, China Carbon Market Centre, Tsinghua University.

[15] International Carbon Action Partnership, China Releases Draft Interim Regulations on the Management of Carbon Emissions Trading. https://icapcarbonaction.com/en/newsarchive/628-china-releases-draft-interim-regulations-on-the-management-of-carbonemissions-trading 
[16] Zhang, Z., Carbon Emissions Trading in China: The Evolution from Pilots to a Nationwide Scheme, Working Paper 1503, Crawford School of Public Policy Centre for Climate Economics\& Policy, Australian National University, 14, 2015. Available at: https://ccep.crawford.anu.edu.au/publication/ccep-working-paper/5535/carbon-emissions-trading-china-evolution-pilots-nationwide

[17] Ministry of Ecology and Environment (MEE), Carbon Emissions Trading Management Measures (Trial) [碳排放权交易管理办法（试行）], MEE Order No. (2021) 16, 31 December 2020 (effective 1 February 2021).

[18] Interview with Yu Zexia and Tian Yiran at Hubei Carbon Exchange, Wuhan, 6 January 2020. Yu Zexia is Manager and Tian Yiran is Vice Manger of the trading department, Hubei Carbon Exchange.

[19] International Carbon Action Partnership (ICAP) ETS Detailed Information: China, Hubei', https://icapcarbonaction.com/en/?option=com_etsmap\&task=export\&format= pdf\&layout $=$ list\&systems $\% 5 \mathrm{~B} \% 5 \mathrm{D}=58$

[20] Interview with Yan Lei and Professor Liu Yonggong, China Agricultural University, Beijing, 19 December 2019. Yan Lei is a Senior Manager in the Carbon Trading Center of the China Beijing Environmental Exchange.

[21] Hua, Y. \& Dong, F., China's carbon market development and carbon market connection: A literature review. Energies, 12(9), p. 1663, 2019. https://doi.org/10.3390/en12091663

[22] Interview with Guo Wei, Chen Zhibin and Jia Hui, offices of Sino Carbon, Beijing, 18 December 2019.

[23] Deng, Z., Li, D., Pang, T. \& Duan, M., Effectiveness of pilot carbon emissions trading systems in China. Climate Policy, 18(8), pp. 992-1011, 2018. https://doi.org/10.1080/ 14693062.2018.1438245

[24] Zeng X., Duan, M., Yu, Z., Li, W., Li, M. \& Liang, X., Data-related challenges and solutions in building China's national carbon emissions trading scheme. Climate Policy, 18, sup1, pp. 90-105, 2018. https://doi.org/10.1080/14693062.2018.1473239 